\title{
Comparação de dois métodos de elaboração e validação de escala diagramática para a quantificação da severidade da mancha de Cylindrocladium em eucalipto
}

\author{
Vítor Flávio Furtado Damasceno ${ }^{1}$, Edson Luiz Furtado², Pedro José Ferreira Filho ${ }^{1, *}$
}

${ }^{1}$ Departamento de Ciências Ambientais, Universidade Federal de São Carlos - UFSCar, Rodovia João Leme dos Santos, Km 110-SP 264, Itinga, 18052-780, Sorocaba, SP, Brasil; ${ }^{2}$ Departamento de Proteção Vegetal, Faculdade de Ciências Agronômicas, UNESP - Campus de Botucatu, Rua José Barbosa de Barros, 1780, Cx. Postal 237, 18610-307, Botucatu, SP, Brasil.

Autor para correspondência: Pedro José Ferreira Filho (pedrojf@ufscar.br)

Data de chegada: 17/12/2013. Aceito para publicação em: 28/07/2014.

$10.1590 / 0100-5405 / 1960$

\section{RESUMO}

Damasceno, V.F.F.; Furtado, E.L.; Ferreira Filho, P.J.. Comparação de dois métodos de elaboração e validação de escala diagramática para a quantificação da severidade da mancha de Cylindrocladium em eucalipto. Summa Phytopathologica, v.40, n.3, p.248-255, 2014.

A mancha de Cylindrocladium em Eucalyptus (Myrtaceae) apresenta ampla ocorrência em campo, causando danos com desfolha a partir do primeiro ano de plantio. A necessidade de quantificação da doença e ausência de escalas confiáveis já publicadas, gerou a necessidade da elaboração e validação de uma escala diagramática para avaliar a mancha de Cylindrocladium spp. em cultivos de eucalipto. O estudo foi desenvolvido no município de Botucatu, São Paulo, Brasil, em talhão de E. grandis com, aproximadamente, dois anos de idade, espaçamento de 2,5 x 3,0 metros, em condições de epidemia em campo. Cem folhas de E. grandis foram coletadas e digitalizadas com uso de escâner e elaboradas duas escalas, a primeira realizada pelo software AFSoft para classificar as cores referentes às áreas saudáveis e lesionadas, e a segunda por meio de delimitação manual com auxílio de mesa digitalizadora com tratamento nos softwares GIMP e ImageJ. Após, determinou-se a severidade em função da distribuição da amostra. Para o teste de acuidade visual e validação das escalas, as folhas foram submetidas à avaliação de severidade, sem e com escala por dez avaliadores (cinco para cada escala), seguida de análise de regressão. A comparação das escalas mostrou que podem ser utilizadas para quantificar a severidade da mancha de Cylindrocladium spp. em E. grandis, com maior acurácia e precisão no segundo método. O AFSoft é indicado para elaboração de escalas com pequena variação entre as tonalidades da amostragem e menor tempo de trabalho, no contrário indica-se a delimitação manual com auxílio de mesa digitalizadora.

Palavras-chave adicionais: AFSoft, doença foliar, epidemiologia, fitopatometria, ImageJ.

\section{ABSTRACT}

Damasceno, V.F.F.; Furtado, E.L.; Ferreira Filho, P.J.. Comparison of two methods to elaborate and validate a diagrammatic scale for quantifying the severity of Cylindrocladium leaf spot on Eucalyptus. Summa Phytopathologica, v.40, n.3, p.248-255, 2014.

Cylindrocladium leaf spot on Eucalyptus (Myrtaceae) presents high occurrence in the field, causing losses due to defoliation since the first year of planting. The need of quantifying the disease and the lack of already published reliable scales have generated the need of elaborating and validating a diagrammatic scale to evaluate Cylindrocladium spp. leaf spot on eucalyptus crops. The study was developed in Botucatu, São Paulo, Brazil, in an E. grandis crop aged approximately two years and showing $2.5 \times 3.0$ meters spacing under epidemic conditions in the field. One hundred E. grandis leaves were collected and digitalized by using a scanner, and two scales were elaborated, the first one performed by AFSoft software to rate colors related to healthy and injured areas and the second one by manual delineating with the aid of a tablet and image treatment on GIMP and ImageJ software. Then, severity was determined based on the sample distribution. For the visual acuity test and validation of scales, leaves were subjected to severity evaluation, without and with scale, by ten raters (five for each scale), followed by regression analysis. Comparison of scales showed that they can be used to quantify the severity of Cyllindrocladium spp. leaf spot on E. grandis, showing higher accuracy and precision with the second method. AFSoft is indicated for the elaboration of scales with small variation among the sampling tonalities and shorter work time; otherwise, manual delineating by using a tablet is indicated.

Additional keywords: AFSoft, leaf disease, epidemiology, phytopatometry, ImageJ.

O cultivo florestal no Brasil atingiu em 2012, 7.185.943 ha, com $70,8 \%$ de espécies de eucalipto, 22,0\% de Pinus spp. e 7,2\% de outras espécies como acácia, araucária, pópulus, teca, seringueira e paricá (1). Dentre a variedade de espécies cultivadas do gênero Eucalyptus, uma das mais difundidas no Brasil é a E. grandis Hill ex. Maiden (Myrtaceae), destinada à produção de celulose e papel, carvão, lenha, laminação, serraria e movelaria (25). Com a intensificação dos plantios, houve aumento da possibilidade de ocorrência de doenças, principalmente nos estágios iniciais de desenvolvimento (6).
Várias espécies de Cylindrocladium estão relacionadas a doenças em viveiros e campo, dentre as quais $C$. candelabrum e C. pteridis têm apresentado maior ocorrência em território brasileiro, sendo as principais doenças causadas em Eucalyptus a podridão de estacas, tombamento e a mancha foliar (2). A mancha de Cylindrocladium é uma das principais doenças do eucalipto, apresentando ampla ocorrência no campo, sendo observada desde 1973, no Brasil, com mais de 15 espécies de eucalipto atacadas pelo patógeno (16).

Os sintomas em plantas infectadas são manchas que progridem 
radialmente em direção à nervura principal ou pecíolo, com origem no ápice e bordas do limbo foliar, podendo ocupar grande proporção da folha. A coloração dessa mancha foliar varia entre diferentes tons de marrom e cinza, com delimitação por halo clorótico, que separa o tecido necrosado do tecido sadio, induzindo desfolha nos terços basal, mediano e apical das copas de árvores a partir do primeiro ano de cultivo $(2,16)$.

Dentre os métodos de avaliação existentes para doenças de plantas são utilizados a incidência e a severidade. O primeiro é um método simples, expressa em porcentagem de plantas doentes em uma amostra e a segunda expressa pela percentagem de tecido doente em relação ao total de tecido avaliado. Para evitar subjetividade na avaliação da severidade se faz necessário a comparação com um diagrama padrão, denominado escala diagramática.

As escalas diagramáticas são obtidas a partir de ilustrações de sintomas da doença em diferentes níveis de intensidade, na planta inteira ou em partes, sendo esse o método mais utilizado para avaliar a severidade (2). Escalas diagramáticas apresentam diversos usos podendo auxiliar na quantificação dos danos, classificação da severidade de ocorrência no plantio, resistência varietal e utilização para experimentos de controle da doença, permitindo verificar se o controle é eficiente ou não (29).

A acuidade visual do olho humano é inversamente proporcional ao logarítmo do estímulo recebido, segundo a lei Weber-Fechner, e o fato de que a melhor visualização para tecidos sadios ocorre acima de $50 \%$ e para tecidos lesionados abaixo de $50 \%$, esses fatos levaram a proposta de escala não-linear para a quantificação da severidade de doenças em plantas $(13,29)$. A severidade pode ser estimada por meio de escalas diagramáticas (8), utilizando-se imagens digitalizadas e aplicativos computacionais (28) ou medindo a extensão da lesão (2). Existem escalas diagramáticas para quantificação da severidade de diversas doenças como: mancha de micosferela em Eucalyptus globulus (23), brusone em trigo (19), helmintosporiose em milho (17), cercosporiose em folhas de cafeeiro (10), mancha alvo em folhas de pepineiro (28), mancha de Quambalarya eucalypti em eucalipto (5), ferrugem do eucalipto $(15,30)$, clorose variegada em citros (4), antracnose em maracujá (11), mancha de isariopsis em videira (18), bacteriose em pessegueiro (9) e míldio em meloeiro (21).

O objetivo deste trabalho foi comparar dois métodos para elaboração de escala diagramática para a quantificação da severidade da mancha de Cylindrocladium spp. em E. grandis.

\section{MATERIAL E MÉTODOS}

\section{Local de estudo}

A elaboração e validação da escala diagramática para avaliação da mancha de Cylindrocladium spp. foi realizada em folhas E. grandis. Esse trabalho foi desenvolvido no município de Botucatu, São Paulo, Brasil (Lat. 22 48' S Long. 48 $23^{\circ}$ ' O e 591 metros a.n.m) em um talhão de E. grandis com, aproximadamente, dois anos de idade e espaçamento de 2,5 x 3,0 metros, em condições de epidemia em campo.

\section{Elaboaração das escalas diagramáticas}

Cem folhas de E. grandis foram coletadas e levadas ao laboratório onde foram digitalizadas com um escâner de mesa modelo HP Scanjet 5590, resultando em imagens com resolução de 200 dpi. No primeiro método utilizado, as imagens foram carregadas no software AFSoft (Embrapa Instrumentação Agropecuária, Unidade São Carlos, São Paulo), para classificar as cores referentes às áreas sadias e lesionadas.
Após a classificação, as imagens foram submetidas a contraste para delimitação da área foliar, e retorno da imagem com as áreas classificadas e com respectivas porcentagens (área sadia ou não).

No segundo método, as imagens foram submetidas a tratamento no software GIMP para a sua edição e feita a delimitação das áreas necróticas com auxílio de mesa digitalizadora, para permitir a mensuração das áreas pelo software ImageJ. Após foi realizado cálculo da porcentagem lesionada com base na área infectada em relação a área total. Neste sentido, seguindo a lei da acuidade visual proposta por Weber-Fechner, com incrementos logarítmicos sucessivos (13, 14) foram definidos os intervalos da severidade utilizados na escala, com início no menor nível da severidade da mancha foliar até o maior detectado. Intervalos intermediários foram inseridos entre os níveis acima de $25 \%$ para melhor orientação do avaliador (4).

A inserção de intervalos intermediários e ajustes nos níveis da escala foram definidos após análises preliminares, porque os avaliadores tiveram dificuldades em estimar valores de severidade na faixa composta pelos intervalos mais longos (16 e 32\%; 32 e 64\%), fazendo com que muitas estimativas apresentassem erros em relação ao valor correto da amostragem, aproximando-se, mais dos níveis vizinhos do que o nível correto. Com a finalidade de facilitar o trabalho dos avaliadores e reduzir os erros das estimativas com uso da escala elaborada, a estratégia adotada foi de inserir níveis, como relatado para elaboração da escala da clorose variegada do citros (4). Neste caso, a Lei Weber-Fechner aplica-se de forma essencial para a elaboração desta escala, permitindo ajustes para melhor orientação dos avaliadores, como verificado nesse trabalho.

As folhas de eucalipto utilizadas para elaboração das escalas diagramáticas foram escolhidas na amostragem em função de apresentar os níveis da severidade da mancha de Cylindrocladium próximos aos níveis previamente calculados.

\section{Validação das escalas diagramáticas}

Dez avaliadores realizaram a análise das 100 folhas com diferentes severidades para a validação das escalas da mancha de Cylindrocladium spp., com cinco avaliadores para cada escala. Todos os avaliadores não possuíam experiência neste tipo de análise. As avaliações da severidade foram realizadas sem e com auxílio da escala. Após a avaliação, foi determinado o desempenho dos avaliadores quanto à precisão das estimativas obtidas com um coeficiente de determinação e pela acurácia e variância dos erros absolutos (12).

A acurácia e precisão das estimativas visuais de cada avaliador foram determinadas por regressão linear simples, considerando severidade real como variável independente e a severidade estimada como variável dependente. A precisão das estimativas foi avaliada pelo coeficiente de determinação $\left(\mathrm{R}^{2}\right)$ e pela variância dos erros absolutos (severidade estimada menos severidade real). Após análise, os dois métodos de elaboração e os dados de validação de ambas as escalas foram comparados.

\section{RESULTADOS E DISCUSSÃO}

\section{Escalas diagramáticas e definição dos níveis da severidade}

As escalas diagramáticas para mancha foliar de cilindrocladio, em folhas de E. grandis, foram elaboradas em função da distribuição da amostra, onde o primeiro nível representa a menor severidade encontrada e o último a máxima, sendo representados pelos valores $1,84 \%$ e $83,75 \%$ para primeira escala, e $0,95 \%$ e $83,84 \%$ para segunda. Os níveis intermediários foram propostos exponencialmente, segundo a 
lei Weber-Fechner (13). Desta maneira, a escala elaborada com auxílio do software AFSoft apresentou oito níveis de severidade em função da distribuição da amostra, sendo I: até 1,84\% de necrose; II: 3,94\%; III: 7,76\%; IV: 16,82\%; V: 24,15\%; VI: 41,42\%; VII: 54,49\% e VIII: $83,75 \%$ (Figura 1). Seguindo a mesma proposta, a escala elaborada através da delimitação manual com auxílio da mesa digitalizadora apresentou as seguintes severidades: I: até $0,95 \%$ de necrose; II: 3,11\%;
III: 8,44\%; IV: 16,10\%; V: 25,68\%; VI: 42,10\%; VII: 56,10\% e VIII: $83,84 \%$ (Figura 2).

Os intervalos sugeridos por Horsfall \& Barratt (13) são compostos por dez intervalos: I: 0 a 3\%; II: 3 a 6\%; III: 6 a 12\%; IV: 12 a 25\%; V: 25 a 50\%; VI: 50 a 75\%; VII: 75 a 88\%; VIII: 88 a 94\%; IX: 94 a 97\%; e X: 97 a 100\%, quando o mínimo é 0, e o máximo é 100\%. Devido à grande amplitude dos níveis V e VI, foram inseridas em ambas as escalas



$1,84 \%$

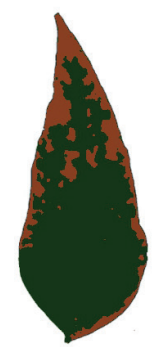

$24,15 \%$

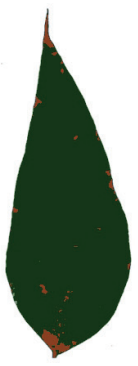

$3,94 \%$

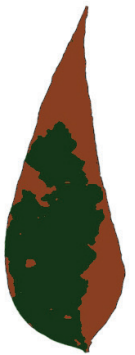

$\mathbf{4 1 , 4 2 \%}$

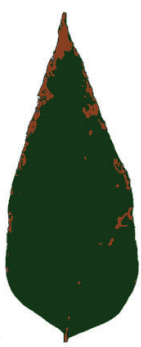

$7,76 \%$

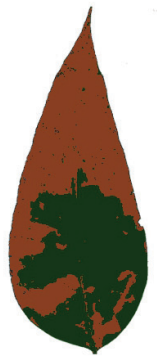

$54,49 \%$

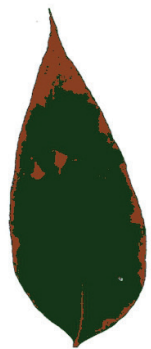

$16,82 \%$



$83,75 \%$

Figura 1. Escala diagramática para avaliação da severidade da mancha de Cylindrocladium spp. em Eucalyptus grandis elaborada pelo software AFSoft. Valores em porcentagem da área foliar com os sintomas.
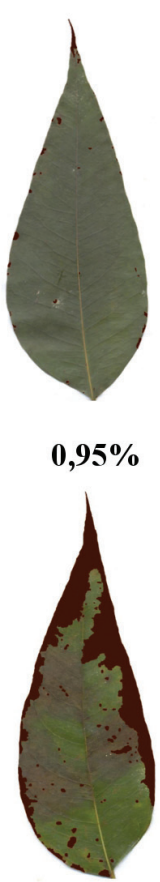

$25,68 \%$

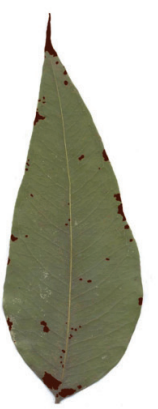

$3,11 \%$



$\mathbf{4 2 , 1 0 \%}$

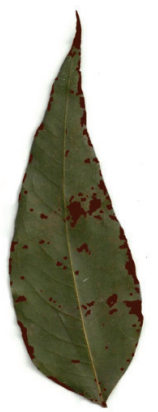

$\mathbf{8 , 4 4 \%}$

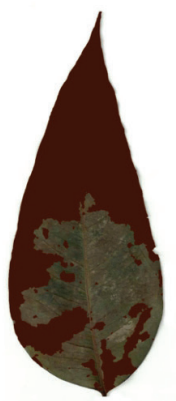

$56,10 \%$

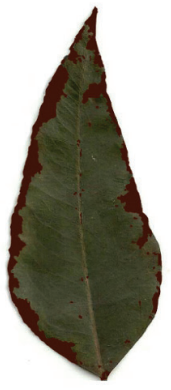

$16,10 \%$

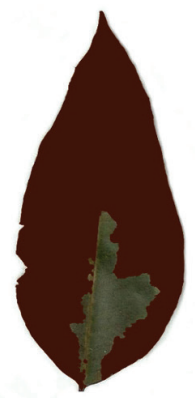

$83,84 \%$

Figura 2. Escala diagramática para avaliação da severidade da mancha de Cylindrocladium spp. em Eucalyptus grandis elaborada por delimitação manual com auxílio de mesa digitalizadora. Valores em porcentagem da área foliar com os sintomas. 

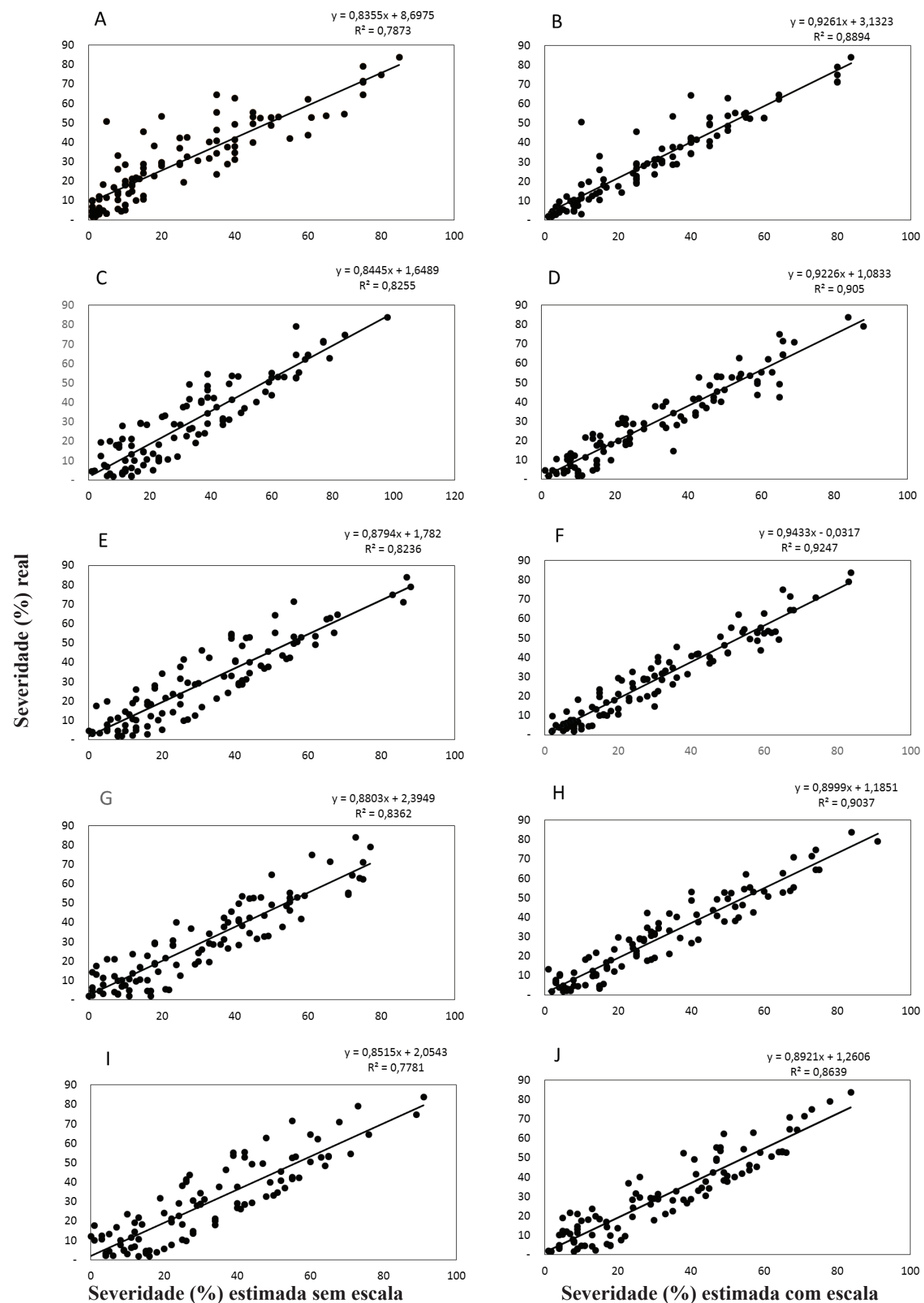

Figura 3. Relação da severidade estimada sem e com auxílio da escala diagramática elaborada no AFSoft (pontos) e linhas de regressão obtidas entre a severidade real e severidade estimada (linha cheia) para mancha de Cylindrocladium spp. em Eucalyptus grandis. A e B: avaliador 1 sem e com escala. C e D: avaliador 2 sem e com escala. E e F: avaliador 3 sem e com escala. G e H: avaliador 4 sem e com escala. I e J: avaliador 5 sem e com escala. 

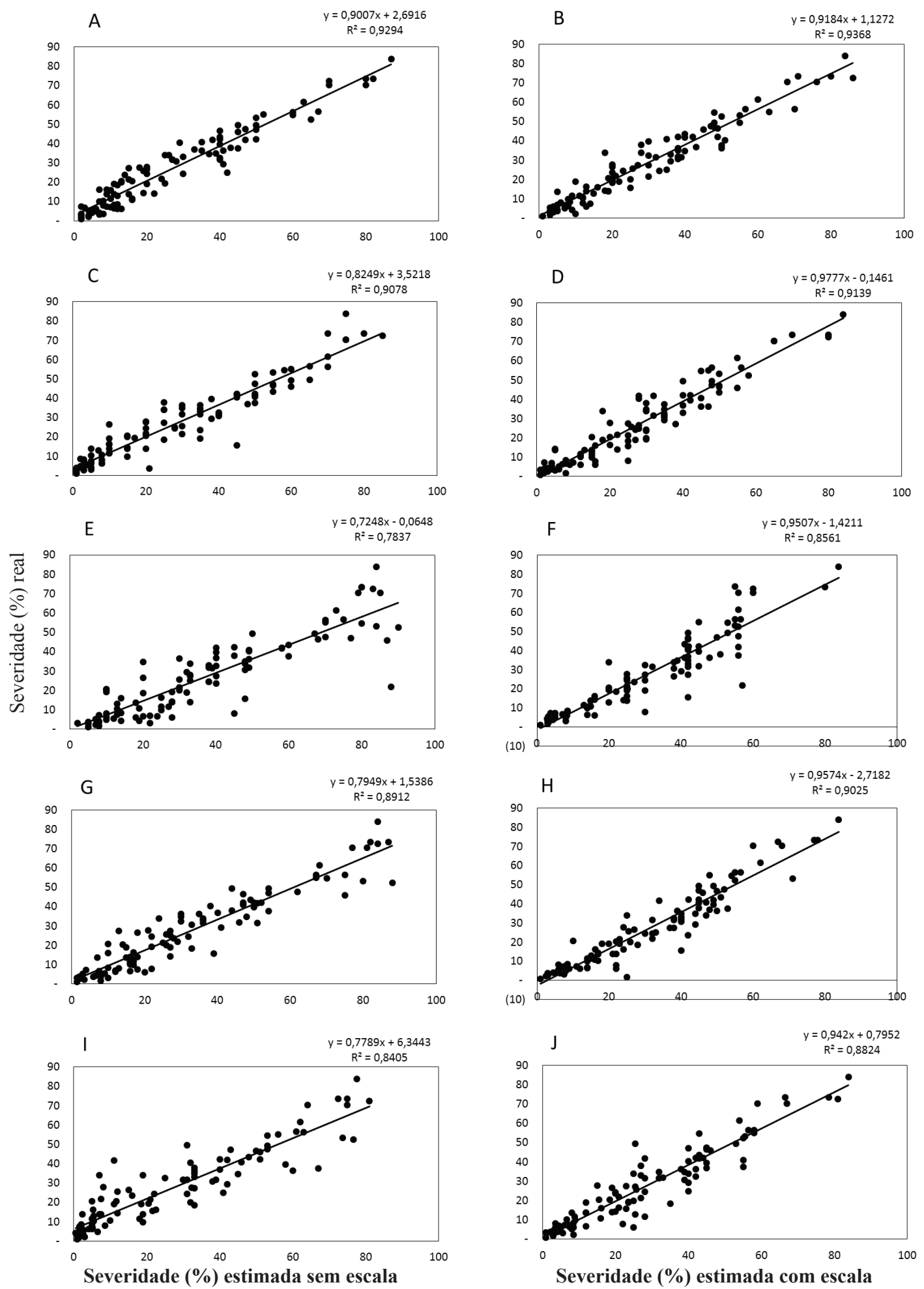

Figura 4. Relação da severidade estimada sem e com auxílio da escala diagramática elaborada com delimitação manual (pontos) e linhas de regressão obtidas entre a severidade real e severidade estimada (linha cheia) para mancha de Cylindrocladium spp. em Eucalyptus grandis. A e B: avaliador 1 sem e com escala. C e D: avaliador 2 sem e com escala. E e F: avaliador 3 sem e com escala. G e H: avaliador 4 sem e com escala. I e J: avaliador 5 sem e com escala. 
níveis de severidade com menor espaçamento para melhor orientação dos avaliadores e diminuir possíveis discrepâncias nas análises.

Na validação das escalas diagramáticas, os avaliadores tiveram boa acurácia, pois os valores estimados de severidade ficaram próximos dos valores da severidade real, determinando a acurácia das avaliações (8).

Os resultados obtidos através das análises foram utilizados na confecção de gráficos de regressão representando a frequência da mancha foliar de cilindrocladio em diferentes intervalos de severidade. Pela proximidade dos valores de severidade estimados aos valores de severidade real, a validação da escala diagramática pode gerar resultados positivos quanto a sua utilização para avaliação manchas de Cylindrocladium spp. em folhas de E. grandis. A utilização dessa escala diagramática para avaliação de manchas de Cylindrocladium spp. em outras espécies e híbridos de eucalipto, deve ser estuda pela existência de diferenças em níveis inter e intraespecíficos, como, estrutura anatômica e composição química de cada planta (27). As análises de regressão foram obtidas para a escala elaborada no AFSoft e para a escala com delimitação manual com coeficientes de determinação $\mathrm{R}^{2}$ inseridos junto aos gráficos (Figuras 3 e 4 ).

Os coeficientes angulares (a) e lineares (b) foram obtidos nas regressões entre severidade real e estimada da mancha foliar a partir de folhas de E. grandis sem e com uso de escala diagramática elaborada no AFSOFT e com delimitação manual e mesa digitalizadora (Tabelas 1 e 2). Para os dados relacionados à escala elaborada no AFSOFT, foram obtidos valores médios de coeficiente angular igual a 0,86 e 0,92; coeficiente linear igual a 3,32 e 1,33; e coeficiente de determinação igual a 0,81 e 0,90, valores obtidos das análises sem e com uso de escala, respectivamente. Já para os dados relacionados à escala elaborada com delimitação manual e mesa digitalizadora, foram obtidos os valores médios de coeficiente angular igual a 0,80 e 0,95 ; coeficiente linear igual a 2,81 e -0,47; e coeficiente de determinação igual a 0,87 e 0,90 , valores obtidos das análises sem e com uso de escala, respectivamente. Os coeficientes por avaliador e as médias gerais, também foram utilizadas como critério de comparação (Tabelas 1 e 2).

A acurácia pode ser quantificada pelo coeficiente angular e pela interseção de linhas de regressão entre a severidade real e suas estimativas, e quanto mais próximo de 1 for o coeficiente angular e mais próximo de 0 for a interseção, maior a acurácia. A precisão pode ser quantificada através do coeficiente de determinação de regressões lineares entre a severidade real e as estimativas, sendo a precisão maior quanto mais perto de 1 for o coeficiente de determinação (3). Desta maneira, observa-se que todos avaliadores apresentaram um aumento na precisão e acurácia nas avaliações com uso de escala em relação as avaliações sem escala, conforme relatado para trabalhos de elaboração e validação de escalas diagramáticas $(9,11,17,18,19,23,26)$, mostrando a importância desta ferramenta na avaliação de severidade de doenças em plantas. Apesar de não ter sido efetuado treinamento para os avaliadores, os resultados se mostraram equivalentes ou superiores quando comparados com trabalhos de elaboração de escalas com treinamento e avaliações posteriores a esse treinamento $(5,7,20,24)$, sugerindo que a mancha de Cylindrocladium spp. seja uma doença com certa facilidade de quantificação visual, além da boa acurácia e

Tabela 1. Coeficientes angulares (a) e lineares (b) e de determinação $\left(R^{2}\right)$, obtidos nas regressões entre severidade real e estimada da doença, com e sem auxílio da escala diagramática elaborada pelo AFSoft.

\begin{tabular}{cccccccc}
\hline & & \multicolumn{5}{c}{ Avaliadores } \\
\cline { 3 - 7 } & & \multicolumn{7}{c}{ AFSoft } \\
\hline \multirow{2}{*}{ Escala } & Coeficientes & 1 & 2 & 3 & 4 & 5 & Média \\
\hline \multirow{2}{*}{ Sem } & $\mathrm{a}$ & 0,84 & 0,84 & 0,88 & 0,88 & 0,85 & 0,86 \\
& $\mathrm{~b}$ & 8,70 & 1,65 & 1,78 & 2,39 & 2,05 & 3,32 \\
& $\mathrm{R}^{2}$ & 0,79 & 0,83 & 0,82 & 0,84 & 0,78 & 0,81 \\
\hline \multirow{2}{*}{ Com } & $\mathrm{a}$ & 0,93 & 0,92 & 0,94 & 0,90 & 0,89 & 0,92 \\
& $\mathrm{~b}$ & 3,13 & 1,08 & $-0,03$ & 1,19 & 1,26 & 1,33 \\
& $\mathrm{R}$ & 0,89 & 0,91 & 0,92 & 0,90 & 0,86 & 0,90 \\
\hline
\end{tabular}

Tabela 2. Coeficientes angulares (a) e lineares (b) e de determinação $\left(\mathrm{R}^{2}\right)$, obtidos nas regressões entre severidade real e estimada da doença, com e sem auxílio da escala diagramática elaborada com delimitação manual em mesa digitalizadora

\begin{tabular}{llllllll}
\hline \multicolumn{7}{c}{ Avaliadores } \\
\cline { 3 - 7 } & \multicolumn{7}{l}{ Delimitação manual (mesa digitalizadora) } \\
\hline Escala & Coeficientes & 1 & 2 & 3 & 4 & 5 & Média \\
\hline \multirow{2}{*}{ Sem } & $\mathrm{a}$ & 0,90 & 0,82 & 0,72 & 0,79 & 0,78 & 0,80 \\
& $\mathrm{~b}$ & 2,69 & 3,52 & $-0,06$ & 1,54 & 6,34 & 2,81 \\
& $\mathrm{R}^{2}$ & 0,93 & 0,91 & 0,78 & 0,89 & 0,84 & 0,87 \\
\hline \multirow{2}{*}{ Com } & $\mathrm{a}$ & 0,92 & 0,98 & 0,95 & 0,96 & 0,94 & 0,95 \\
& $\mathrm{~b}$ & 1,13 & $-0,15$ & $-1,42$ & $-2,72$ & 0,80 & $-0,47$ \\
& $\mathrm{R}^{2}$ & 0,94 & 0,91 & 0,86 & 0,90 & 0,88 & 0,90 \\
\hline
\end{tabular}


precisão dos avaliadores selecionados.

Os avaliadores apresentaram boa repetibilidade nas estimativas, o que pode ser observado nos resultados da regressão entre a primeira (sem escala) e a segunda avaliação (com escala). Parâmetros de uma equação de regressão, como os coeficientes angular, linear e de determinação, podem ser utilizados para comparar a acurácia de métodos e avaliadores (22). Comparativamente, as duas escalas apresentaram certa proximidade entre os valores médios dos coeficientes das avaliações, onde houve leve vantagem em acurácia e precisão nas avaliações feitas para a escala elaborada com delimitação manual com auxílio da mesa digitalizadora. Isto pode ter ocorrido em função deste método necessitar de maior detalhe por parte do elaborador, pois nele as lesões são delimitadas uma a uma, folha por folha, enquanto no AFSoft as folhas são classificadas por padrões organizados previamente. $O$ fato do software AFSoft trabalhar com padrões, implica em análise rápida, uma vez que o programa permite análise em lotes (várias folhas por vez). Isto pode ser um problema quando as folhas da amostragem apresentam grande variação na tonalidade de suas cores, tanto para tecidos sadios como lesionados, tornando necessário a criação de novos padrões para analisar uma única folha. Dentro da análise de folha única podem ser encontradas dificuldades com relação às tonalidades, podendo haver coincidência de tons de lesão e fundo quando a lesão é próxima ao branco, e entre tecidos lesionados e nervuras, quando a nervura se apresenta em tons escuros.

Os softwares GIMP (delimitação) e ImageJ (mensuração), foram utilizados no segundo método, e não foram encontrados problemas, conforme o primeiro, pois o operador possuía controle completo das atividades. Foi detectado problema com à delimitação feita para aplicar a binarização, e consequente mensuração dos tecidos da folha, realizada pelo AFSoft, não coincidindo exatamente com a borda das folhas na maioria dos casos. Já a binarização realizada pelo ImageJ, no segundo método, coincidiu exatamente com os limites das folhas.

As escalas diagramáticas podem ser utilizadas para a quantificação da severidade de mancha de Cylindrocladium spp. em E. grandis. O AFSoft é indicado para elaboração de escalas com pequena variação entre as tonalidades da amostragem e menor tempo de trabalho, no contrário indica-se a delimitação manual com auxílio de mesa digitalizadora.

\section{AGRADECIMENTOS}

À "Fundação de Estudos e Pesquisas Agrícolas e Florestais (FEPAF)" pelo suporte financeiro e à empresa Silvicontrol pelo apoio na instalação e condução do experimento.

\section{REFERÊNCIAS}

1. Associação Brasileira de Produtores de Florestas Plantadas. Anuário estatístico da ABRAF: ano base 2012/ABRAF. - Brasília, DF, 2013. 148p. Disponível em: <http://abraflor.org.br/estatisticas/ABRAF13/ABRAF13_BR.pdf>. Acesso em: 18 nov. 2013.

2. Alfenas, A.C.; Zauza, E.A.V.; Mafia, R.G.; Assis, T.F. Clonagem e doenças do eucalipto. $2^{a}$. ed. Viçosa: Editora UFV, 2009. 500p.

3. Amorim, L.; Bergamin Filho, A. Fenologia, patometria e quantificação de danos. In: Amorim, L.; Rezende, J.A.M.; Bergamin Filho, A. Manual de fitopatologia. 4a . ed. Piracicaba: Agronômica Ceres, 2011. v.1, cap.33, p.517-542.

4. Amorim, L.; Bergamin Filho, A.; Palazzo, D.; Bassanezi, R.B.; Godoy, C.V.; Torres, G.A.M. Clorose variegada dos citros: uma escala diagramática para avaliação da severidade da doença. Fitopatologia Brasileira, Brasília, DF, v.18, n.2, p.174-180, 1993.

5. Andrade, G.C.G.; Alfenas, A.C., Mafia, R.G., Maffia, L.A.; Gonçalves, R.C. Escala diagramática para avaliação da severidade da mancha foliar do eucalipto causada por Quambalaria eucalypti. Fitopatologia Brasileira, Brasília, DF, v.30, n.5, p.504-509, out. 2005.

6. Aparecido, C.C.; Furtado, E.L.; Figueiredo, M.B. Caracterização morfofisiológica de isolados do gênero Cylindrocladium. Summa Phytopathologica, Botucatu, v.34, n.1, p.38-47, 2008.

7. Barbosa, M.A.G.; Michereff, S.J.; Mora-Aguilera, G. Elaboração e validação de escala diagramática para avaliação da severidade da ferrugem branca do crisântemo. Summa Phytopathologica, Botucatu, v.32, n.1, p.57-62, 2006.

8. Bergamin Filho, A.; Amorim, L. Doenças de plantas tropicais: epidemiologia e controle econômico. São Paulo: Agronômica Ceres, 1996. 299p.

9. Citadin, I.; Assmann, A.P.; Mazaro, S.M.; Gouvêa, A.; Danner, M.A.; Malagi, G. Escala diagramática para avaliação da severidade de bacteriose em pessegueiro. Revista Brasileira de Fruticultura, Jaboticabal, v.30, n.2, p.327-330, jun. 2008.

10. Custódio, A.A.P.; Pozza, E.A.; Guimarães, S.S.C.; Koshikumo, E.S.M.; Hoyos J.M.A.; Souza, P.E. Comparison and validation of diagrammatic scales for brown eye spots in coffee tree leaves. Ciência e Agrotecnologia, Lavras, v.35, n.6, p.1067-1076, dez. 2011.

11. Fisher, I.H.; Alves, S.A.M.; Almeida, A.M.; Arruda, M.C.; Bertani, R.M.A.; Garcia, M.J.M. Elaboração e validação de escala diagramática para quantificação da severidade da antracnose em frutos de maracujá amarelo. Summa Phytopathologica, Botucatu, v.35, n.3, p.226-228, set. 2009.

12. Godoy, C.V.; Carneiro, S.M.P.T.G.; Iamauti, M.T.; Pria, M.D.; Amorim, L.; Berger, R.D.; Bergamin Filho. A. Diagrammatic scales for bean diseases: Development and validation. Journal of Plant Disease and Protection, Stuttgart, v.104, n.4, p.336-345, nov. 1997.

13. Horsfall, J.C.; Barrat, R.W. An improved grading system for measuring plant diseases. Phytopathology, St. Paul, v.35, n.8, p.665, 1945.

14. Horsfall, J.G.; Cowling, E.B. Pathometry: the measurement of plant disease. In Horsfall, J.G.; Cowling, E.B. (Ed.) Plant disease: an advanced treatise - how disease develops in populations. New York: Academic Press, 1978. v.2, p.119-136.

15. Junghans, D.T.; Alfenas, A.C.; Maffia, L.A. Escala de notas para quantificação da ferrugem em Eucalyptus. Fitopatologia Brasileira, Brasília, DF, v.28, n.2, p.184-188, abr. 2003.

16. Krugner, T.L.; Auer, C.G. Doenças dos eucaliptos. In: Kimati, H.; Amorim, L.; Rezende, J.A.M.; Filho, A.B.; Camargo, L.E.A. Manual de fitopatologia. São Paulo: Ceres, 2005. v.2, p.327-328.Lazaroto, A.; Santos, I.; Konflaz, V.A.; Malagi, G.; Camochena, R.C. Escala diagramática para avaliação de severidade da helmintosporiose comum em milho. Ciência Rural, Santa Maria, v.42, n.12, p.2288-2294, dez. 2012.

17. Lazaroto, A.; Santos, I.; Konflaz, V.A.; Malagi, G.; Camochena, R.C. Escala diagramática para avaliação de severidade da helmintosporiose comum em milho. Ciência Rural, Santa Maria, v.42, n.12, p.2288-2294, dez. 2012.

18. Lenz, G.; Costa, I.D.; Balardin, R.S.; Marques, L.N.; Arrué, A.; Stefanelo, M.S.; Zemolin, R.S. Elaboração e validação de escala diagramática para quantificação da mancha de isariopsis da videira. Ciência Rural, Santa Maria, v.39, n.8, p.2516-2520, nov. 2009.

19. Maciel, J.L.N; Danelli, A.L.D.; Boaretto, C.; Forcelini, C.A. Diagrammatic scale for the assessment of blast on wheat spikes. Summa Phytopathologica, Botucatu, v.39, n.3, p.162-166, sept. 2013.

20. Michereff, S.J.; Noronha, M.A.; Andrade, D.E.G.T.; Oliveira, E.P.; Xavier Filha, M.S.; Moreira, P.A.A. Elaboração e validação de escala diagramática para a cercosporiose do pimentão. Summa Phytopathologica, Botucatu,v.32, n.3, p.260-266, 2006.

21. Michereff, S.J.; Noronha, M.A.; Lima, G.S.A; Albert, I.C.L.; Melo, E.A.; Gusmão, L.O. Diagrammatic scale to assess downy mildew severity in melon. Horticultura Brasileira, Brasília, DF, v.27, n.1, mar. 2009.

22. Nutter JR, F.W.; Schultz, P.M. Improving the accuracy and precision of disease assessments: selection of methods and use of computer-aided training programs. Canadian Journal of Plant Pathology, Otawa, v.17, n.2, p.174-184, 1995.

23. Passador, M.M.; Porcena, A.S.; Masson, M.V.; de Pieri, C.; Finkenauer, E.; Furtado, E.L. Escala diagramática para quantificação da severidade de manchas em folhas de Eucalyptus globulus Labill. causadas por Teratosphaeria nubilosa (Cooke) Crous \& U. Braun. Ciência Florestal, Santa Maria, v.23, n.2, p.523-530, abr. 2013.

24. Santos, P.H.D.; Vivas, M.; Silveira, S.F.; Silva, J.M.; Terra, C.E.P.S. Ela- 
boração e validação de escala diagramática para avaliação da severidade de oídio em folhas de mamoeiro. Summa Phytopathologica, Botucatu, v.37, n.4, p.215-217, 2011.

25. Souza, C.R., Rossi, L.M.B., Azevedo, C.P., Lima, R.B. Comportamento da Acacia mangium e de clones de Eucalyptus grandis $\mathrm{x}$ Eucalyptus urophylla em plantios experimentais na Amazônia Central. Scientia Forestalis, Piracicaba, v.65, p.95-101, 2004

26. Teramoto, A; Aguiar, R.A; Garcia, R.A.; Martins, M.C.; Cunha, M.G. Escala diagramática para avaliação da severidade da mancha alvo em folhas de pepineiro. Pesquisa Agropecuária Tropical, Goiânia, v.41, n.3, set. 2011.

27. Tomazello Filho, M. Estrutura anatômica de oito espécies de eucalipto cultivadas no Brasil. Piracicaba: IPEF, 1985. 31p.
28. Vale, F.X.R.; Fernandes Filho, E.I.; Liberato, J.R. QUANT. A software plant disease severity assessment. In: International Congress of Plant Pathology, 8th., 2003, New Zealand. Anais. New Zealand: Christchurch, 2003. p.105.

29. Vale, F.X.R. do; Junior, W.C. de J.; Liberato, J.R.; Souza, C.A. Quantificação de doenças e do crescimento do hospedeiro. In: Vale, F. X. R. do; Junior, W. C. de J.; Zambolim, L. Epidemiologia aplicada ao manejo de doenças de plantas. Belo Horizonte: Editora Perffil, 2004. p.98-102.

30. Zamprogno, K.C.; Furtado, E.L.; Marino, C.L.; Bonine, C.A.; Dias, D.C. Use of bulked segregant analysis in identification of molecular markers linked to resistance to rust (Puccinia psidii Winter) in Eucalyptus sp. Summa Phytopathologica, Botucatu, v.34, n.3, p.253-255, 2008. 